\title{
RESEARCH COMMITEE \\ A Course on Research Methodology and Statistics
}

\author{
By I. F. Brockington \\ Department of Psychiatry, University Hospital of South Manchester
}

A course on Research Methodology and Statistics sponsored jointly by the Research Committee and the Department of Postgraduate Studies, Manchester University, was held in the Department of Psychiatry, University Hospital of South Manchester on $5 / 6$ and 26/27 November 1977.

The course followed the approach adopted by Professor Max Hamilton last year at Leeds. Students were asked to read general texts on research methodology and elementary statistics before the first weekend, and were given protocols to write during the three-week recess before the second weekend.

Eight lectures on general methodology were given - 'What research is all about' (Professor Hamilton), 'The research protocol' (Professor Goldberg), 'Sampling and controls' (Dr Brockington), 'Rating and measurement' (Dr Hall). 'Searching the literature (Mr Kenna), 'Principles of statistical analysis' (Dr Vaughan), 'The use of computers' (Mrs Hillier), and 'The interpretation of results and publication' (Mr Kenna). For two lectures and one seminar students were offered a choice of methods of social study (Dr Maguire and Dr Huxley) or methods of clinical study (Dr Szabadi, Dr Johnson and Dr Brockington). There were two statistical exercises, one dealing with the comparison of means and the other with con-

\section{NORTH WEST DIVISION}

The Annual Dinner of the North West Division will be held on Saturday, 6 May, at the Excelsior Hotel, Manchester Airport. Further information is available from Dr H. Eaton, West Cheshire Hospital, Liverpool Road, Chester CHI 2BA, or Dr D. A. W. Johnson, Department of Psychiatry, Withington Hospital, West Didsbury, Manchester M20 8LR. tingency tables and correlation. There was one seminar on 'The life history of a research project', an optional seminar on multivariate statistics and the rest of the time was given to the discussion of the research protocols. At the final meeting the best six protocols were presented to the whole group and a prize (a framed print of old Manchester) was given to the winning entry (an investigation of childbirth as a stressful event in fathers, submitted by $\mathrm{Dr} C$. Thomas.)

Twenty-nine students took part: one geriatrician, one social worker, one research worker on a metabolic unit, one from industry, four from community, social or tropical medicine and the rest psychiatrists. Six were of consultant grade, and there was one professor. Twelve came from Manchester, four from Liverpool and the rest from further afield.

Feedback was positive and everyone seemed to have thought that the course was worth their time and money $(£ 44)$. The protocol exercise was particularly appreciated, but some students would have liked to have more time to prepare them, and to have written them on subjects of their own choice. The handouts given with almost every lecture were well received. One student asked to see a copy of an ideal research protocol'; would any member of the College be prepared to supply one?

\section{MIDLAND DIVISION}

Please note that the Spring Meeting of the Midland Division will take place on Friday, 28 April, not 21 April as shown in the College's Calendar. The venue will be Powick Hospital, Worcester. Full details will be circulated later. 